\title{
Laparoscopy-Assisted Percutaneous Gastrostomy Tube Placement along with Laparoscopic Gastropexy
}

\author{
Hironori Tsujimoto Yoshihisa Yaguchi Isao Kumano Yusuke Matsumoto \\ Kazumichi Yoshida Kazuo Hase \\ Department of Surgery, National Defense Medical College, Tokorozawa, Japan
}

\section{Key Words}

Laparoscopic gastrostomy · Gastropexy $\cdot$ Minimally

invasive surgery

\begin{abstract}
Background: Percutaneous endoscopic gastrostomy (PEG) has gained wide acceptance for patients suffering malnutrition. However, the PEG technique is not always feasible in cases in which endoscopic passage is not possible due to an obstruction in the esophagus. Methods: Under general anesthesia, a 2.0 nylon suture with a straight needle was inserted into the peritoneal cavity approximately $1 \mathrm{~cm}$ cranial to the planned gastrostomy. After this straight needle was held with the laparoscopic needle holder, the layers of the anterior gastric wall were sutured, and then the needle was put through the abdominal wall. The same procedures were performed at $2 \mathrm{~cm}$ on the caudal side of the first suture. A trocar with a peel-away sheath was used to penetrate the gastric wall. The peel-away sheath was removed and a balloon catheter was placed between the two gastropexy sutures. Results: This surgical procedure was performed in 6 cases. The mean operation time was $46.7 \pm 10.0 \mathrm{~min}$, the postoperative courses were uneventful, and feeding was
\end{abstract}

started on postoperative day 1 in all cases. Conclusions: This laparoscopic gastrostomy procedure should be especially useful in patients in whom endoscopic passage is not possible due to a neck or esophageal stenosis.

Copyright $\odot 2011$ S. Karger AG, Basel

\section{Introduction}

Since percutaneous endoscopic gastrostomy (PEG) was first introduced in 1980 by Gauderer and Ponsky for pediatric patients with inadequate nutritional intake [1], it has revolutionized feeding tube placement by providing a safe and reliable method for performing gastrostomy, while avoiding laparotomy, and having a low level of associated morbidity. PEG has gained wide acceptance, and over 200,000 PEGs are performed annually in the United States [2]. Since the introduction of PEG, several new techniques have been proposed, including a PEG modification using a peel-away sheath by Russell et al. [3] and a double-lumen intestinal tube percutaneous gastrostomy procedure by Preshaw [4] for a safe and confident tube insertion. However, the various PEG techniques at present have several limitations with regard to tube place-

\section{KARGER}

Fax +4161306 1234 E-Mail karger@karger.ch www.karger.com
(C) 2011 S. Karger AG, Basel

0253-4886/11/0283-0163\$38.00/0

Accessible online at:

www.karger.com/dsu
Hironori Tsujimoto, MD

Department of Surgery, National Defense Medical College

3-2 Namiki

Tokorozawa 359-8513 (Japan)

Tel. +81 42995 1637, E-Mail tsujihi@ndmc.ac.jp 
ment; this method is not always feasible or safe, e.g. in cases in which endoscopic passage is not possible due to an obstruction in the neck or esophageal cancer. In addition, transillumination may be difficult due to morbid obesity, ascites, or the colon or liver overlying the stomach [5]. In these cases, direct puncture of the stomach is the only way to gain access. Surgery has been proven to be a reliable and safe method of catheter gastrostomy, although it has the disadvantage of the need for passage through a relatively large incision in the gastric mucosa and the abdominal wall.

Several modified procedures of laparoscopic gastrostomy have been introduced [5-10]. These procedures do not always allow gastropexy. The necessity of a gastropexy is still a controversial discussion, as there is the danger of catheter dislocation, possibly resulting in serious complications arising from using introduction methods without gastropexy.

In this paper, we introduce a minimally invasive laparoscopic gastrostomy with a simple laparoscopic gastropexy using two nylon sutures with a straight needle [11].

\section{Methods}

\section{Surgical Procedures}

After the induction of general anesthesia, the patient was placed in a supine position. The surgeon and the laparoscopist stood on the right side of the patient and the first assistant on the left side. A camera port was inserted into an inferior umbilical incision. Next, a pneumoperitoneum of $10 \mathrm{~mm} \mathrm{Hg}$ was created, and two additional ports with a diameter of $5 \mathrm{~mm}$ were inserted into the right upper and right lower quadrants under laparoscopic imaging. In the last 3 cases, the procedures were performed by means of a single $2-\mathrm{cm}$ umbilical incision.

After exploration of the peritoneal cavity, the desired position for placement of the gastrostomy was located on the anterior abdominal wall and digital palpation was performed at the site of planned gastrostomy under direct laparoscopic visualization. A 2.0 nylon suture with a straight needle (Ethicon, Tokyo, Japan) was inserted into the peritoneal cavity approximately $1 \mathrm{~cm}$ from the cranial side of the planned gastrostomy. After this straight needle was held with the laparoscopic needle holder, the layers of the anterior gastric wall were sutured (fig. 1a), and then the needle was put through the abdominal wall (fig. 1b). The same procedures were performed at approximately $2 \mathrm{~cm}$ on the caudal side of the first suture. After cutaneous incision between the sutures was made, trocar with a peel-away sheath (Create Medic Co., Ltd., Yokohama, Japan) was used to penetrate the gastric wall (fig. 1c). The peel-away sheath was removed and a balloon catheter $(13 \mathrm{Fr}$, Create Medic Co., Ltd.) was placed between the two gastropexy sutures (fig. 2). A radiographic examination was performed to confirm the gastrostomy tube had been adequately placed in the stomach after the completion of these procedures.
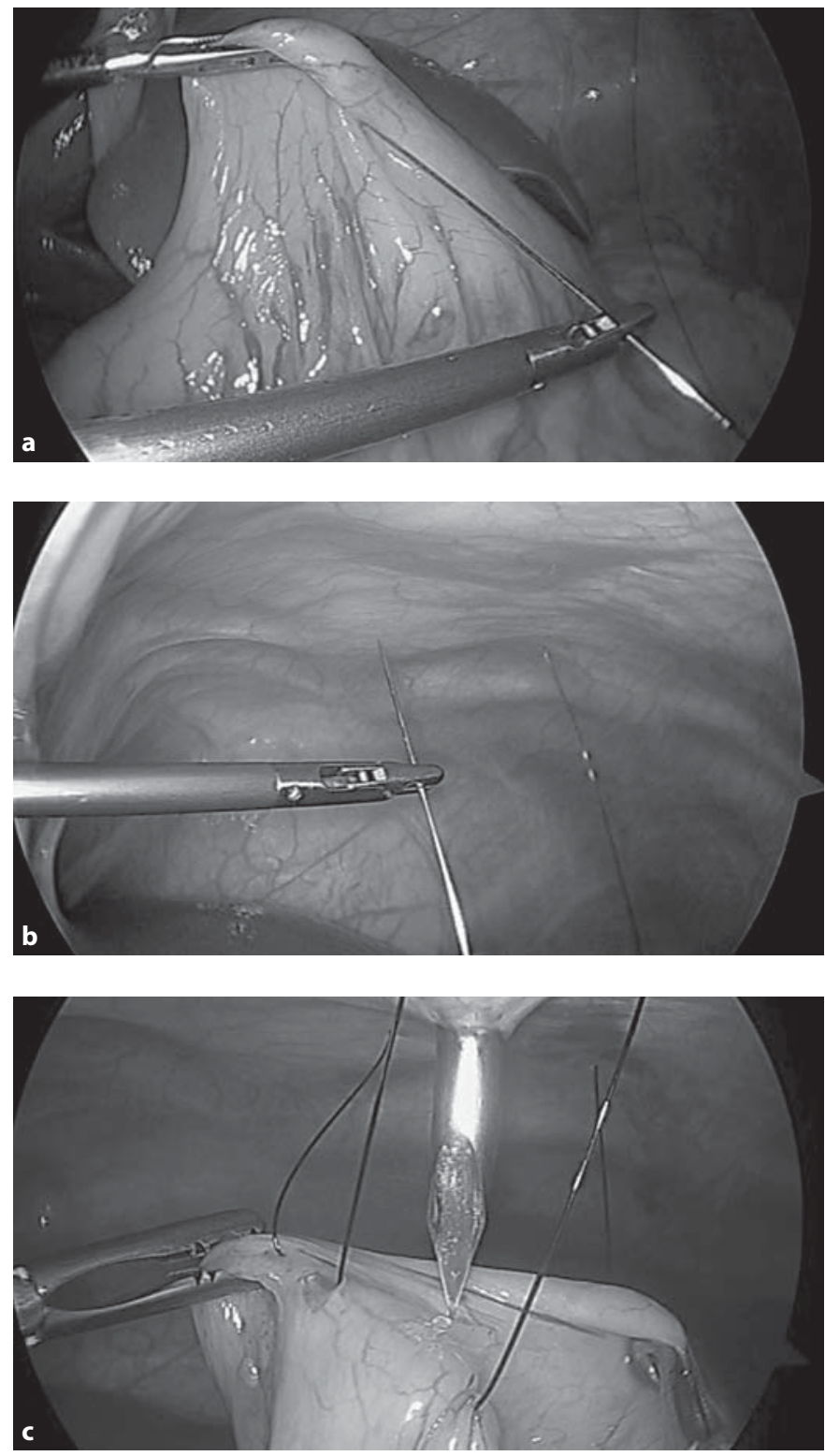

Fig. 1. Laparoscopic view of the laparoscopic gastrostomy with gastropexy using two straight needles. After exploration of the peritoneal cavity, the desired position for placement of the gastrostomy is located on the anterior abdominal wall, and digital palpation was performed at the site of the planned gastrostomy under direct laparoscopic visualization. A 2.0 nylon suture with a straight needle was inserted into the peritoneal cavity approximately $1 \mathrm{~cm}$ from the cranial side of the planned gastrostomy. After this straight needle was held using the laparoscopic needle holder, the layers of the anterior gastric wall were sutured (a), and then the needle was put through the abdominal wall (b). The same procedures were performed at approximately $2 \mathrm{~cm}$ on the caudal side of the first suture. After a cutaneous incision was made between the sutures, a trocar with a peel-away sheath was used to penetrate the gastric wall (c). The peel-away sheath was removed and a balloon catheter was placed between the two gastropexy sutures.

Tsujimoto/Yaguchi/Kumano/ Matsumoto/Yoshida/Hase 
Table 1. Demographic data in 6 patients

\begin{tabular}{|c|c|c|c|c|c|c|}
\hline $\begin{array}{l}\text { Patient } \\
\text { No. }\end{array}$ & Age & Sex & Primary cause & $\begin{array}{l}\text { Lenght of } \\
\text { operation } \\
\text { min }\end{array}$ & $\begin{array}{l}\text { Length of } \\
\text { hospital stay } \\
\text { days }\end{array}$ & SILS \\
\hline 1 & 52 & M & idiopathic laryngeal stenosis & 54 & 5 & no \\
\hline 2 & 71 & M & esophageal cancer & 57 & $4(3)$ & no \\
\hline 3 & 72 & $\mathrm{M}$ & esophageal cancer & 39 & $3(6)$ & no \\
\hline 4 & 67 & $\mathrm{M}$ & esophageal cancer & 36 & 5 & yes \\
\hline 5 & 57 & $\mathrm{~F}$ & laryngeal cancer & 35 & 6 & yes \\
\hline 6 & 63 & $\mathrm{~F}$ & esophageal cancer & 59 & $3(8)$ & yes \\
\hline
\end{tabular}

SILS = Single incision laparoscopic surgery. Length of hospital stay was prolonged due to the chemoradiotherapy for esophageal cancer in cases 2, 3 and 6. Additional hospital stay needed for the chemoradiotherapy is indicated in parentheses.

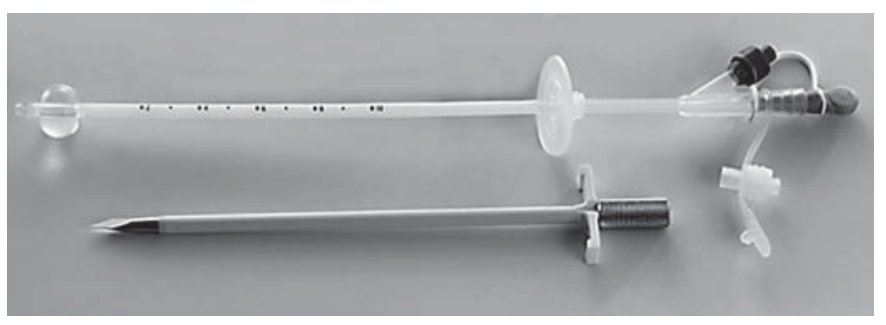

Fig. 2. Trocar with a peel-away sheath and a balloon catheter $(13 \mathrm{Fr}$, Create Medic Co., Ltd., Yokohama, Japan) used in the procedures.

\section{Results}

We have safely performed this surgical procedure in 6 patients in whom endoscopic passage was not possible due to a neck obstruction or esophageal stenosis (table 1). The primary causes of obstruction in these patients included 4 cases of esophageal cancer, 1 of idiopathic laryngeal stenosis, and 1 of laryngeal cancer. The mean age of these patients was $63.7 \pm 6.3$ years. The mean operation time was $46.7 \pm 10.0 \mathrm{~min}$. No mortality or morbidity was observed. All patients started enteral nutrition on postoperative day 1 without any clinical trouble. The average length of the postoperative hospital stay was $4.3 \pm 1.2$ days; the length of hospital stay was prolonged due to the chemoradiotherapy for esophageal cancer in 3 cases.

\section{Discussion}

In this study, a technique for laparoscopic gastrostomy with laparoscopic gastropexy is introduced. No mortality or morbidity was associated with the procedure, and en- teral feeding was started the day after surgery in all patients.

Although PEG is the established standard procedure for gastrostomy, it cannot be performed in all patients. For example, it is not possible to perform PEG in patients in whom endoscopic passage is not allowed, or there is a blockage of the gastrostomy tube due to a tumor or bleeding. In these cases, surgery or radiologic methods should be employed. However, open surgery has the disadvantage of the need for passage through a relatively large incision in the gastric mucosa and the abdominal wall, and radiologic methods may not be able to penetrate the organs overlying the stomach due to obesity or previous upper abdominal surgery.

Although the sutureless 'pull method' for PEG does not allow confident gastropexy, it has become a widespread endoscopic technique for transcutaneous gastric long-term nutrition. However, if the gastropexy was not successfully performed, early dislodgement of the PEG tube may lead to be peritonitis, and blind reinsertion should not be attempted [12]. Furthermore, gastropexy has the advantage of preventing gastric hemorrhage, inadvertent tube migration into the peritoneum, and leakage of gastric contents into the peritoneal cavity [13]. Thus, laparoscopy-assisted percutaneous gastrostomy tube placement along with laparoscopic gastropexy presented here should be a safe and feasible method for patients in whom endoscopic passage is not feasible.

A double-lumen gastropexy device with a loop which allows the placement of a suture, i.e. a 'Funada style' kit, has been widely employed as a simple and feasible introduction method for gastropexy $[9,14]$. Dormann et al. [14] reported that long-term follow-up in patients with gastrostomy using this gastropexy kit revealed only $2.1 \%$ 
peristomal infection, and without any serious complications. Bolder et al. [6] demonstrated that percutaneous laparoscopically assisted gastrostomy to provide enteral access for patients with pharyngoesophageal obstruction was not suitable for PEG placement. Our laparoscopic gastropexy method using two straight needles is an application of this kit for laparoscopic surgery, and this method is easy and safe even for surgeons with limited laparoscopic surgery experience. Indeed, the procedures in 5 of the 6 patients in this study were performed by residents and fellows under staff supervision. However, this surgical procedure should not be undertaken in patients with direct extension of the tumor into the proximal stomach or high-risk patients for whom general anesthesia is not suitable.
In conclusion, this minimally invasive gastrostomy procedure, although it does require general anesthesia, should prove to be especially useful in patients in whom endoscopic passage is not possible due to a neck obstruction or esophageal stenosis, or who are suspected of having organs overlying the stomach due to obesity or previous upper abdominal surgery.

\section{Acknowledgements}

The authors greatly thank Shuichi Hiraki, Naoko Sakamoto, Takuya Horio, Risa Takahata, Hiroyuki Horiguchi, Shinsuke Nomura, Satoshi Ono, and Junji Yamamoto, Department of Surgery, National Defense Medical College, for their critical revision.

\section{References}

1 Gauderer MW, Ponsky JL, Izant RJ Jr: Gastrostomy without laparotomy: a percutaneous endoscopic technique. J Pediatr Surg 1980;15:872-875

$\checkmark 2$ Gauderer MW: Percutaneous endoscopic gastrostomy - 20 years later: a historical perspective. J Pediatr Surg 2001;36:217-219.

-3 Russell TR, Brotman M, Norris F: Percutaneous gastrostomy: a new simplified and costeffective technique. Am J Surg 1984;148: 132-137.

4 Preshaw RM: A percutaneous method for inserting a feeding gastrostomy tube. Surg Gynecol Obstet 1981;152:658-660.

5 Kandil E, Alabbas H, Jacob C, Friedlander P, Duchesne J, Joshi V, Bellows C: A simple and safe minimally invasive technique for laparoscopic gastrostomy. JSLS 2010;14:62-65.
6 6 Bolder U, Scherer MN, Schmidt T, Hornung M, Schlitt HJ, Vogel P: Percutaneous laparoscopic assisted gastrostomy (PLAG) - a new technique for cases of pharyngoesophageal obstruction. Langenbecks Arch Surg 2010; 395:1107-1113.

7 Idowu O, Driggs XA, Kim S: Laparoscopically assisted antegrade percutaneous endoscopic gastrostomy. J Pediatr Surg 2010;45: $277-279$.

8 Lopes G, Salcone M, Neff M: Laparoscopicassisted percutaneous endoscopic gastrostomy tube placement. JSLS 2010;14:66-69.

-9 Sakai H, Inamori M, Iida H, Akimoto K, Endo H, Nozaki Y, Akiyama T, Sakamoto Y, Fujita K, Takahashi H, Yoneda M, Abe Y, Kubota K, Ueno N, Kusakabe A, Nakajima A: Recovery of a misinserted gastrostomy tube during replacement: effectiveness of gastropexy using a 'Funada style' kit. Digestion 2007;75:179.

10 Molloy M, Ose KJ, Bower RH: Laparoscopic Janeway gastrostomy: an alternative to celiotomy for the management of a dislodged percutaneous gastrostomy. J Am Coll Surg 1997;185:187-189.
11 Tsujimoto H, Hiraki S, Sugasawa H, Yaguchi Y, Sakamoto N, Fujino K, Aiko S, Ono S, Ichikura T, Hase K: A case report of laparoscopic gastrostomy for idiopathic laryngeal stenosis. J Natl Def Med Coll 2009;34:30-34.

12 Minchff TV: Early dislodgement of percutaneous and endoscopic gastrostomy tube. J S C Med Assoc 2007;103:13-15.

-13 Saini S, Mueller PR, Gaa J, Briggs SE, Hahn PF, Forman BH, Tung GA, Silverman SG, Lee MJ, Morrison MC: Percutaneous gastrostomy with gastropexy: experience in 125 patients. AJR Am J Roentgenol 1990;154:10031006.

14 Dormann AJ, Wejda B, Kahl S, Huchzermeyer H, Ebert MP, Malfertheiner P: Long-term results with a new introducer method with gastropexy for percutaneous endoscopic gastrostomy. Am J Gastroenterol 2006;101: 1229-1234. 